\title{
Effects of Marxist Methodology on Social Science Researches Conducted by Vietnamese Scholars Before 1986
}

\author{
Nguyen Thi Mai Hoa (Ruan Shi Mei Hua) \\ Marxism School of Hunan University, Changsha city, Hunan, China \\ Institute of Philosophy,Vietnam Academy of Social Sciences, Ha Noi, Viet Nam \\ Shu Yuan Zhao \\ Marxism School of Hunan University, Changsha city, Hunan, China
}

In the early twentieth century, Marxism was propagated into Vietnam through patriotic intellectuals. After the propagation into Vietnam, Marxism not only influenced national liberation movements, but also profoundly affected scholars, particularly scholars of social science. In fact, many of well-known Vietnamese scholars have relied on Marxism's theory of social existence and social consciousness, infrastructure and superstructure, practical concept, concept of class struggle, etc. to comment on poetry, history, language, geography, philosophy, etc. In other words, the scholars have applied Marxist methodology to explore and study cultural and social life in Vietnam; and in that way, a generation of Marxist researchers in the field of social sciences has been formed. After the renovation of the country, the Government of Vietnam has implemented its policy of openness and international integration, and scholars have been therefore able to receive many other Western ideals and cultures, and the Marxist methodology was not the only one used in social science research. Consequently, some people expressed their skepticism about the role of Marxist methodology in academic research in Vietnam, even completely denied the historical significance of Marxist methodology to the academia in Vietnam. This article is intended, through Vietnamese Marxist scholars, especially the ones in the field of social sciences prior to 1986 (i.e., prior to the renovation of the country) to demonstrate the historical significance of the Marxist methodology to the Vietnamese academia. It is clear that the penetration of the Marxism and the Marxist methodology into Vietnam have created a revolution in the field of academic research (primarily in the field of social science). It has promoted academic research from conservative toward innovative, from traditional to modern. With the presence of the French colonialism as well as the French culture, the Marxism and the Marxist methodology helped Vietnamese scholars break away from Chinese Confucian scholarship and shift to systematic scholarly studies based on practical bases, scientific bases and modern methods. Although there are still some certain drawbacks, it cannot be denied that the Marxism and the Marxist methodology have played an important role in the formation and development of modern social sciences in Vietnam today.

Keywords: Marxist methodology, Vietnam, scholars, social science

\footnotetext{
Nguyen Thi Mai Hoa (Ruan Shi Mei Hua), Doctoral Student, Marxism School of Hunan University, Changsha city, Hunan, China; Institute of Philosophy,Vietnam Academy of Social Sciences, Ha Noi, Viet Nam.

Shu Yuan Zhao, Professor, Marxism School of Hunan University, Changsha city, Hunan, China.
} 


\section{World View and Marxist Methodology}

In a general sense, the world view is general concepts of human beings about the world and themselves. And the Marxist world view is a system of dialectical materialist ideas about the world and human beings. Let us return to Marx's "The German Ideology" (this work represents the maturation of Marx's thoughts in the world of dialectical materialism and historical materialism) to clarify his dialectical materialist worldview (also Marxist worldview).

Natural world from Marx's conception is the one in which man can feel about it, influence it, modify it for their purposes, that is, the world is real. Marx also said that the natural world does not exist passively, but thanks to transformation by human, and the natural world is constantly changing, moving and developing. In this respect, it can be seen that the natural world is the product of man, the product of history. However, it is not a pure product of the human mind, but rather a product of human real activity which is the material production. He wrote: "That activity, that labor, that unceasing material creation and that production are bases of the whole sensible world, just as the existing world" ". In Marx's theory, the natural world is also the living and working environment of human beings, and the natural world provides human beings with materials for living and thinking. Therefore, it can be said that human beings base on the natural world to live, and human beings are a part of the natural world. While FeuerBach only saw the natural world as a simple and naked one, then Marx saw the intimate relationship between the natural world and human beings: human beings impacted on the natural world, and vice versa, the natural world also impacted on human beings and their consciousness. In his "The German Ideology," Marx asserted that the history of the natural world was completely realistic, realized by humans through their actual activity. He wrote: the history of the natural world "is not any abstract action of "self-consciousness", spirit of the world, or any metaphysical ghost, but a purely physical action that can be tested by experience or an action of each individual — just as he or she is in real life, eating, drinking and dressing —is a proof" ${ }^{\prime 2}$. In fact, the history of the natural world is the process by which human beings use materials and tools of the natural world to carry out the transformation of the world in order to satisfy their needs for survival and development; during that process, human beings made the natural world and themselves gradually transformed. This process goes from generation to generation.

On the human side, unlike the contemporary German idealistic philosophy, Marx did not use the premises of ideology or reasoning, but used the material production and real life of human beings to explain the nature of human beings as well as their position in the world. Thus, human beings from Marx's conception are not abstract human beings or imaginable human beings, but real human beings living and working in certain historical circumstances and able to feel with experience. As to nature of human beings, according to Marx, human beings are natural, because they have bone, meat, and essential needs such as eating, wearing, living etc. and live thanks to certain natural conditions. Natural world is "inorganic human body" and "inorganic human spirit". Marx also said that through the physical production and the building of social life, the natural part inside human beings gradually completed and "manifested as the basis of human existence of human beings", that is to say, it tends to become the nature of human society. He emphasized that only when in the social life, the natural part inside

\footnotetext{
${ }^{1}$ Full set of K. Marx and F. Engels, Vol. 3, National Political Publishing House, 1995, p. 63

${ }^{2}$ Full set of K. Marx and F. Engels, Vol. 3, National Political Publishing House, 1995, p. 65
} 
human beings can be manifested as the human nature of human beings. Thus, apart from the nature, human beings also have a social nature. As to the position of human beings in the world, Marx asserted that human beings are the subject of the natural world, the subject of human social history. But human beings did not create the natural world and human social history with pure thoughts, but with material realities and real activities. Human beings, through the material production, have transformed the natural world according to their purposes and ideals, these are "the natural world manifested as the work of human beings and the reality of human beings", at the same time also created the history of human society. As to the consciousness of human beings, Marx believed that human consciousness is not something that exists outside of human beings, or precedes human beings, but consciousness belongs to real human beings. The consciousness of human beings reflects the process of labor and production as well as their real life. He wrote: "Consciousness can never be anything other than the existence of consciousness, and existence of human beings is the process of real life of human beings."3. Thus, products of consciousness, forms of consciousness such as philosophy, religion, morality, metaphysics, etc. also reflect the process of labor, production and real life of human beings. Marx was "on the real ground of history," not in the world of any abstract and mystical ideas, to explain the formation of consciousness, the products of consciousness and the forms of consciousness. He also pointed out that, in order to eradicate the forms of social consciousness, we could not rely on argumentative struggle, but must carry out a real revolution overthrowing the factual basis that produced these forms of consciousness. With the dialectical materialist interpretation of human beings and consciousness of human beings, Marx found common principles such as: social existence determines social consciousness; communication is consistent with the development of the production force; real life is the basis of the formation and development of ideology, reasoning, vice versa, ideology, reasoning must be consistent with real life.

The Marxist methodology is essentially the application of Marx's dialectical materialist worldviews to cognitive activity and real rehabilitation of human beings. In other words, the Marxist dialectical materialist worldviews constitute the content of the Marxist methodology. As part of the Marxist methodology, principles of dialectical materialist worldview no longer serve the purpose of explaining the world and the human beings but act as a guide to cognitive activity and real rehabilitation of human beings. It can be said that all principles of Marxist dialectical materialist worldview are considered Marxist methodology.

\section{Effects of Marxist Methodology on Social Science Researches Conducted by Vietnamese Scholars from the Early Twentieth Century to 1945}

From the beginning of the twentieth century to 1945 , Vietnam remained under the domination of the French colonialist, many movements against the French colonial government and their henchmen broke out, demonstrating the will, determination and courage of the Vietnamese people in realizing the aspiration for national liberation. Although the socio-political situation of Vietnam was very disturbed, this period marked the strong transformation of Vietnam's social structure towards modernization. In that historical context, scholars (mainly scholars of social science research) have faced two tendencies to receive cultural thoughts from outside Vietnam: firstly, modern culture from Western Europe (mainly from France); second, Marx's aesthetic, cultural,

${ }^{3}$ Full set of K. Marx and F. Engels, Vol. 3, National Political Publishing House, 1995, p. 37 
social and political ideology from Soviet Union (including the Marxist methodology). Scholars toward the first tendency were considered bourgeois romans, whose ideas contained modern and advanced elements of Western capitalist countries; these scholars include Thieu Son, Hoai Thanh, Luu Trong Lu, Le Trang Kieu, Phan Van Dat, Le Quang Loc, etc. However, after the successful August Revolution of 1945 in Vietnam, most of these scholars gradually accepted the Marxist methodology in their research works and became Marxist researchers. While scholars toward the second tendency were patriotic revolutionary militants, most of whom have been involved in struggles for national independence, and their ideologies showed the stance of the proletariat supporting the national liberation revolution; these scholars include: Ho Xanh, Lam Mong Quang, Hai Thanh, Hai Trieu, Tran Huy Lieu, Dao Duy Anh, Trinh Xuan An, Dang Thai Mai, Vu Ngọc Phan, Nhu Phong, Ha Xuan Truong, Hong Chuong, etc. They are called true Marxists.

In comparison with contemporary scholars, the adoption of the Marxist methodology was more evident in Hai Trieu's research works of literary\&art and philosophy. In the field of literary art, he pointed out that literature\&art was inseparable from the economic and social life of the human beings, without the" art for art's sake", and literature\&art must come from the very economic and social life of human beings to build its contents, images and value. In other words, literary\&art must honestly reflect the economic and social life of human beings (in the "Literature and Materialism", Hai Trieu has introduced the concept of "description of social reality"). He wrote: "The more an artistic or fine art work makes the social character clear, the more it is valuable. In other words, if a work expresses common sentiment of majority of people in an age (majority of whom can enjoy art), then that work will be welcomed"4. From the reality of the country in the 1930s of the twentieth century, Hai Trieu affirmed that literature\&art must serve political struggles of the nation, "literature in any age must also reflect class struggle in that age"; there is no literature as outsider of any class struggles and national liberation struggles. If the first tendency-oriented scholars can realize literature\&art as a field of human emotional excitement, according to Hai Trieu, literary\&art is simply a sharp theoretical weapon to fight politically. In the field of philosophy, the "General Marxism" (1938) by Hai Trieu succinctly and systematically interprets the basic dialectical materialist principles of the Marxism, and is considered to make valuable contribution to revolutionary movements of national liberation and academic life of the country at the time. It can be said that Hai Trieu is an enthusiastic patriotic revolutionary militant in the literature\&art front, with undeniable merits in building the revolutionary literature\&art of Vietnam in the early twentieth century.

Dao Duy Anh is also considered a typical Marxist scholar in this stage. He applied the Marxist methodology to study the history of Vietnamese culture and thought, especially Confucianism. In the "Confucianism's criticism" (1938), Dao Duy Anh pointed out that the survival of a kind of ideology, or a social regime in a certain stage, is decided by economic factors of that stage. He wrote: "a social regime is transformed due to many reasons such as thoughts, religious beliefs, race, geography, etc., but the most important reason is economic conditions.In a word, a social regime reflects the economy of that social system" (Dao Duy Anh, 1938, p. 27). In this way, Dao Duy Anh did not base on conservative and backward doctrines of Confucianism, but based on economic, political and social conditions of Vietnam between the late nineteenth century and the early twenty first century, to explain the survival of Confucianism in the history of the nation. According to him, the country's economic, political and

\footnotetext{
${ }^{4}$ Full set of Hai Trieu, Vol. 1. Literature Publishing House, Hanoi, 1996, p. 315.
} 
social situation had changed in the trend of modernization, Confucianism was clearly no longer suitable for the new situation, gradually to give room for trends of Western progressive and modern culture. But he also said that there should be no attitude of contempt or negativity of the role of Confucianism in the cultural and social life in Vietnam. He affirmed that Vietnam's modern cultural and social life preserves the positive values of Confucianism and dismisses its negative effects. On the one hand, Dao Duy Anh criticized conservative, backward ideologies of Confucianism as many of contemporary intellectuals, but on the other hand, he regarded Confucianism as an important component of the cultural transmission. He also underlined that "Confucianism in our country has never been studied thoroughly", so it is important to return to serious, scientific and systematic studies of Confucianism in order to realize and accurately assess advantages and disadvantages of this doctrine in the cultural and social life in Vietnam. Dao Duy Anh also relied on Marx's theory on class and class struggle to explain fundamental issues of Confucianism. Many complex thoughts of Confucius and contemporary scholars were examined and resolved by Dao Duy Anh from their stance on landlord class. He wrote: "Confucius is the philosopher representing the thought of new landlord class, while Confucianism is the doctrine representing the dominant and agnostic thought of that class" (Dao Duy Anh, 1938, p. 30)... It can be said that, throughout the "Confucianism's Criticism", Dao Duy Anh applied the Marxist methodology to explain the survival and fundamental problems of Confucianism. In comparison to previous generations, he recognized and evaluated objectively, scientifically and systematically Confucian phenomena. Although the application of Marxist methodology was still fairly rudimentary, Dao Duy Anh was really a pioneer in the study of Confucianism in Vietnam in direction of science, modernization.

Tran Huy Lieu was also known as a great scholar at this stage. He soon adopted the Marxist methodology in the study of the nation's revolutionary history. Tran Huy Lieu was a revolutionary patriotic warrior who was involved in the struggle for national liberation, and a historian. Thus, he did not rely on the available records, but on the facts of the nation he had witnessed to write the nation's revolutionary history. During the resistant war against French colonialist, Tran Huy Lieu compiled two history books, "Brief History of Vietnamese Revolution in Modern Time" and "Draft of Vietnamese Revolution History in 1858-1945" to encourage people's fighting spirit. These two books are not only materials for the revolutionary cause of the nation, but also represent Tran Huy Lieu's new method of writing history, that is the Marxist methodology. After the end of the resistant war against the French colonialist, he compiled "History of 80-Year Anti-France War" (3 volumes); in which he described and analyzed in a deep and vivid way the French colonialist's invasion of Vietnam, the permanent resistance war against French colonialist of the Vietnamese people, the victory of the August Revolution in Vietnam in 1945. In this book, Tran Huy Lieu also demonstrated his ability to adopt the Marxist methodology in approaching and processing abundant data of national history. Later, he still relied on the Marxist methodology to write more books including "History of the August Revolution", "Reference to Modern History of Vietnam" (12 volumes), "History of Hanoi Capital". It can be said that Tran Huy Lieu has written the history of the nation with a sincere and enthusiastic heart and a scientific and modern method. Most of his history books truly reflect the working, production and combat life of the Vietnamese people. He deserves to be considered as the founder of a new history in Vietnam - the history for the nation's revolutionary cause.

Thus, at this stage, the application of the Marxist methodology by scholars to the study of cultural and social life in Vietnam had really opened a new era for Vietnamese academia. For the first time, subjects such as 
literature, history, philosophy, geography, ethnicity, language, etc. were viewed as a science with subject of study, method of study and reasoning system. For the first time, the achievements of the study of these subjects were used for the struggles to build up and defend the nation, to promote movements against the oppression, exploitation and liberation. In this respect, it can be said that Vietnamese Marxist scholars and the Marxist methodology had achieved remarkable successes. However, most Vietnamese Marxist scholars at this stage were the first to explore and apply the Marxist methodology in academic study, so the application of the Marxist methodology was still rigid, rigorous, even somewhat vulgar, dogmatic, not as proficient, profound, and delicate as the later period.

\section{Effects of Marxist Methodology on Social Science Researches Conducted by Vietnamese scholars from 1945 to 1986}

In 1945, the August Revolution against the oppression and exploitation of the French colonialists and the monarchical despotism in Vietnam succeeded, the Democratic Republic of Vietnam was established and used Marxism-Leninism as the sole basis of political theory. In the field of academic research, the Marxist methodology also holds the position of monopoly — which is both ideology and research methodology. Thus, in the period 1945-1986, the activity of receiving Marxist methodology of Vietnamese scholars took place extremely vibrant and achieved many important achievements. This vibrantc atmosphere can be clearly felt through the translation of Marxist documents originating from the Soviet Union. Classics of Marxism were translated into Vietnamese such as, "Marxism and Problems of Linguistics" (1955) by I.V. Stalin; "Party Organisation and Party Literature g" (1957) by V. Lenin; "On Literature and Art" (1958) by Marx and Engels, ... Studies of Soviet scholars were also been translated into Vietnamese such as, "On freedom of artistic creation "(1957) by M. Kuznetsov and Y. Lukin; What is "socialist realism" (1958) by F. Kuznetsov and Trofimov; "Marx, Engels on Literature and Art" (1962) by Jean Freville; "Theory of Literature" (1962) by L.I. Timofeev, "The Marxist Leninist Theological Principle" (1963) of the Soviet Academy of Sciences... Basing on these translation work, universities and research institutes in Vietnam have obtained large books for the teaching and studying of Marxist theory. It is noteworthy that, at this period, the receipt of Marxist methodology by Vietnamese scholars took place in parallel with the Communist Party's political struggle for the purpose to wipe out all the remnants of the research methodology of bourgeois culture and non-Marxist culture, paving the way to building an advanced Marxist study in Vietnam. Most of the documents, reports of the Communist Party and scholarly works of Vietnamese scholars focus on criticism, tackling trends of bourgeois culture and non-Marxist culture for the most important duties. Here, the monographs are as follows, "Anti-opinion of non-proletarian of Mr. Truong Tuu on the Arts and Politics" (1957) by Van Tan and Nguyen Hong Phong; "Western Literature and Humanity" (1969) by Hoang Trinh; "Modern revisionism in the Literature in some countries" (1974) by Hoang Xuan Nhi..., critical essays of the irrational philosophy of Albert Camus, Existentialism of J. P. Sartre, structuralism..., The struggle against the Nhan van—Giai Pham group, "criticism of modern revisionism"...

The period 1945-1986 is considered to be the most brilliant development of the academic Marxist in Vietnam. With faith in the bright future of the nation - independence and successful construction of communist idealist society, Vietnamese scholars (who were also revolutionary soldiers with love of socialism) enthusiastically applied the Marxist methodology to build the academic system of the new regime. At this period, 
scholars such as Dinh Gia Khanh, Cao Huy Dinh, Le Tri Vien, Bui Van Nguyen, Le Dinh Ky, Huynh Ly, Nguyen Luong Ngoc, Truong Chinh... has applied Marxist methodology to study Vietnamese literature. Among them, Dinh Gia Khanh is a pioneer in exploring and developing the folk literature in Vietnam. He is a professor of English and French, but he hardly relies on Western bourgeois materials or theories to carry out research on the Vietnamese folk literature. Dinh Gia Khanh mainly relies on the Marxist methodology and classic works of Marx, Engels to build theories of the Vietnamese folk literature. His researches include: "Collection of Vietnamese poetry from the 10th century to the 17th century" (1962); "History of Vietnamese Literature" (1972) (including Vietnamese folk literature, Vietnamese Literature in the 10th century to the first half of the 18th century, Vietnamese Literature in the end of the 18th century to the end of the 19th century); "Collection of Vietnamese Literature" (42 volumes); "Preliminary study of the problems of fairy tales through the story of Tam and Cam" (1968); "Vietnamese folk culture in the context of Southeast Asian culture" (1993)... In most of these studies, Dinh Gia Khanh starts with a detailed analysis of the social and economic conditions and the specific division class in order to grasp the general rule of each period, then he analyzes the content, image and value of folk stories. According to him, the content, image, and value of folk literature reflect working people' real life as well as their struggles against oppression and exploitation... For Dinh Gia Khanh, the value of literature or folk is expressed in the fact that it is a theoretical weapon serving for the national construction and defense.; specifically, it is linked to the struggle for independence and the path to socialism of the nation. Supporting the view of considering that literature and art are "fronts in politics," Dinh Gia Khanh has repeatedly quoted the documents of Communist Party his folk literature studies. He wanted to use folktales to convey the principles of Communist Party and the socialist ideal to working people. It can be said that Dinh Gia Khanh is a standardly applicant in Marxist methodology and directives in Communist Party documents on academic research.

Among scholars who studied the language at this period, such as Nguyen Tai Can, Hoang Tue, Nguyen Kim Thanh..., Nguyen Lai was the most outstanding scholar. He relied on the Marxist methodology to explore and exploit the values of the traditional language of the nation. Nguyen Lai is particularly interested in the subject of semantics in Vietnamese. According to him, semantics is the world realization of the human that is transmitted into the language. In other words, semantics is the reflection of the real world on language (this reflection is enacted by history, society, culture of the community). In the reflection process, the subject can diminish the non-critical elements, focusing only on the key elements that the subject cares or makes the subject interested in, to search and explore meaningful and valuable things for human life... It can be said, from the beginning, Nguyen Lai has identified the deep social nature of Vietnamese semantics. He also said that in Vietnamese there is never a clear distinction between semantics, which is always the transition from semantics to another, inversion of semantics to another. Nguyen Lai also studied the relationship between semantics and grammar in Vietnamese. He said that the semantics of Vietnamese are very subtle and difficult to define, so it is necessary to have an interpretation of the grammatical structure to grasp the semantic of words in the true sense of the native person. In contrast, semantics also affects grammar. Nguyen Lai is also very attentive to language communication. He conceived, language communication is a form of social activity; through its ability to communicate content, it directs people to realistic action (that is, language behavior, or verbal behavior, or borrowing words). Thus, language communication is both personal and social... Obviously, Nguyen Lai does not just study the traditional language of the nation in theoretical terms, but also in terms of practice. In Nguyen Lai, the dialectical 
materialism is very clear and profound in each of his treatises on the traditional language of the nation. He writes: "How language fluctuates and develops, no matter what to be exploited in any direction. If it is not distorted, it is not separated from the function of orienting social action for human beings, it can not escape the the rule of truth properly discovered through the world view and Marxist methodology" (Nguyen Lai, 1984, p. 87).

Scholars studying ethnic history at this period include: Tran Van Giau, Dinh Xuan Lam, Phan Huy Le, Tran Quoc Vuong, Ha Van Tan... They are all pioneers in the application of new, scientific and modern methodology - Marxist methodology in the study of national history. However, the Marxist character is most apparent in Tran Van Giau's study of national history. First of all, Tran Van Giau applies the theory of Marx's socio-economic form to the divergence of Vietnamese history so that it can explain the events in each period of national history. He also said that it is necessary to flexibly apply this Marx's theory into Vietnam's particular situation, it is not necessary to force this or another period of national history into this socio-economic form or another socio-economic form... Next, Tran Van Giau mainly relies on Marxist world view to write national history. His works include: "Anti-invasion" (1956); "Vietnam history" (1957); "Vietnamese worker class" (1962); "The South keeping stronghold" (1964); "Development of ideology in Vietnam from the 19th century to the August Revolution" (1973)... In these works, national history is not presented that are the history of political parties, leaders, religions or certain groups of people, which is revitalization of the history of the working masses (In other words, the national history reflects the appearance, morality, thoughts, aspirations and activities of the working mass). Although Tran Van Giau chooses the movement of the working masses as the main object as studying the national history, but he did not fall into populism. He still finds the essential interaction between the working mass and the workers and intellectuals, between one is the "workers" and the other is "teachers". Tran Van Giau is also a writer who respects the truth, "events with date, people with name". He always criticized, compared to determine the credibility of the material that he uses; For material that is not really clear, he often notes to the reader carefully, for self-verification. Thus, the history books of Tran Van Giau are considered as vivid, realistic pictures of the working, production and fighting life of the working people in different periods. In the study of national history, Tran Van Giau has clearly applied the Marxist method in a smooth, standard and scientific way, so that he avoided the dogma, mechanical mistacke which was a common mistake of the Marxist scholars in Vietnam and the world at that time. Tran Van Giau as his students have commented, "Marxism was dyed-in-the-wool of his flesh"...

Thus, in the period 1945-1986, Vietnamese scholars accepted the Marxist methodology primarily from Soviet scholars, and considered it the only methodology in academic research. Most scholars wish to apply this scientific and modern methodology to their research, for contributing to the development of an advanced social sciences and humanities in the new era of the nation - era of the nation goes to socialism. The acceptance of Marxist methodology also offers certain advantages for Vietnamese scholars in academic research at this period. First of all, scholars recognize the close connection between academic study and real social life, especially with the revolution of national liberation and the socialism construction of the Party and people. Accordingly, scholars have the basis for rejecting all the arguments of idealism, formalism, artlism, mechanical materialism ... Next, scholars are clearly aware that academic research is the front of ideological struggle for the process of national and humanity liberation. After all, Marxist methodology gives scholars an academic research method which is objective, scientific and systematic... However, since this is the period in which Marxist methodology holds a 
monopoly position, scholars have certain disadvantages. Most of the scholarly work has been politicized, these works are not viewed from the scientific point of view, but they are viewed in terms of their benefit or harmfulness to revolution, or they are judged as having reflected political thoughts correctly or wrong. The essential creativity of researchers gradually gave way to the noble ideals of the collective... Thus, in this respect, it can be said that the acceptance of Marxist methodology is also the acceptance of a research method which is partly rigid, mechanical and extreme, by Vietnamese scholars at this period.

\section{Conclusion}

Marxist methodology in Vietnam before 1986 has the conditions for strong growth and certain achievements, but also having inevitable inadequacies. The Marxist methodology at this time was placed in a unique position, clearly demarcating boundaries with non-Marxist theories and methodologies. This approach has made the Marxist methodology gradually become a closed, extreme and slow method of research. In fact, the Marxist methodology is even considered as a fundamental and important methodology of Vietnamese academic research, it is just a methodology of research in many other research methodologies. It is not an comprehensive methodology that can solve all problems in academic research. Therefore, it is timely for Vietnamese scholars, especially post-1986 scholars (after the country's renovation) to take a more open view of the Marxist methodology. In the face of increasingly diversed variations of Vietnamese academics, the scholars should not completely deny the positive historical value and meaning of the Marxist methodology, it is necessary to gain the advances of other Western research methodology to supplement and overcome the limitations of this methodology, making it one of the most effective methodologies in the current social science and humanity research in Vietnam.

\section{References}

Dao Duy Anh. (1938). Confucianism's criticism. Hue: Quan hai tung thu Publishing House.

Full set of Hai Trieu (Vol. 1). (1996). Hanoi: Literature Publishing House.

Full set of K. Marx and F. Engels (Vol. 3). (1995). Hanoi: National Political Publishing House.

Hai Trieu. (1933). Evolution of literature and the evolution of humanity (Trial of dialectical literature criticizes the relationship of evolution in literature and the evolution of humanity). Posted on "The East", Edition 872.

Institute of History. (2011). Tran Huy Lieu with history. Hanoi: Social Science Publishing House.

Le Xuan Kieu, \& Kieu Mai Son. (2014). The scholar Dao Duy Anh. Hanoi: Literature Publishing House.

Literature Institute. (2014). Professor Dinh Gia Khanh—teacher, pioneering scientist. Hanoi: Youth Publishing House.

Nguyen Lai. (1983). Values and meanings in relation to the nature of the linguistic signal from some theses of Karl Heinrich Marx .

Journal of Language, 8, 90.

Nguyen Lai. (1984). Communication and language from some theses of Marx and Engels. Journal of Social Science, 8.

Tran Van Giau. (2012). A hundred years mark. Hanoi: Youth Publishing House.

Vu Duc Phuc, \& Nguyen Duc Dan. (1964). Draft of Vietnamese literature history (1930-1945). Hanoi: Literature Publishing House. 